\title{
Neurofibromatosis Clinical Trials-REiNS Collaboration 2020 Recommendations
}

\author{
Looking Back and Moving Ahead
}

\begin{abstract}
Andrea M. Gross, MD, Scott R. Plotkin, MD, PhD, and Brigitte C. Widemann, MD, on behalf of the REiNS
\end{abstract} International Collaboration

Neurology ${ }^{\circledR}$ 2021;97:S1-S3. doi:10.1212/WNL.0000000000012429
Correspondence

Dr. Gross

andrea.gross@nih.gov

Neurofibromatosis (NF) type 1 (NF1), NF type 2 (NF2), and schwannomatosis are genetic tumor predisposition syndromes with a wide variety of clinical manifestations. Effective medical treatments for these conditions remain limited. Since its founding in 2011, the Response Evaluation in Neurofibromatosis and Schwannomatosis (REiNS) International Collaboration has worked to develop standardized, practical, and clinically meaningful outcome measures for clinical trials in these conditions. Two previous supplements published in Neurology ${ }^{\circledR}$ in $2013^{1}$ and $2016^{2}$ set forth a variety of recommendations that are summarized in the table.

Since the last supplement was published, the REiNS group has continued to grow and evolve. One major focus has been to increase patient engagement in clinical trial design to ensure that these trials address issues of importance to patients and that trial evaluations and outcome measures are feasible. Thus, a patient representative working group was formed, and patient representatives have become an integral part of all REiNS projects. A second major focus for multiple working groups has been the development of clinical trial endpoints for cutaneous neurofibromas (cNF). This initiative was driven by input from patient representatives who identified $\mathrm{cNF}$ as a major cause of morbidity and by the recent development of targeted therapies that may be able to treat them.

In the introduction to the first supplement, we predicted that "these recommendations will be modified with time as more data on NF-specific endpoints becomes available." In the years since the most recent REiNS recommendations were published, these measures have been used in multiple clinical trials. The recently published phase 2 trial of the MEK inhibitor selumetinib for inoperable plexiform neurofibromas (PN) in children with NF1 used REiNS recommendations to determine key outcome measures and definitions for clinically meaningful change when available. ${ }^{3}$ Some of the practical lessons learned during this and other trials will likely inform future clinical trial designs for this condition.

For example, the REiNS recommendations for clinical trial endpoints for patients with airwayrelated PN provide examples of both successful implementation of the recommendations and areas that will likely need refining for future clinical trials. ${ }^{4}$ Patients with airway-associated PN can have upper or lower airway obstruction if the trachea or bronchi are compressed and may have significant restrictive lung disease if the tumor displaces lung parenchyma. In the selumetinib trial, 16 of 50 patients (32\%) had PN-related airway morbidity. ${ }^{3}$ The REiNS recommendations for airway PN included the use of spirometry and polysomnography, with specific emphasis on the forced expiratory volume in 1 second $\left(\mathrm{FEV}_{1}\right)$ and the apnea-hypopnea index (AHI) from each test, respectively ${ }^{4}$ (table). While the guidelines for improvement in $\mathrm{FEV}_{1}$ were crucial in identifying a clinically meaningful improvement in many of these patients, there were some important limitations to the practical application of the recommendations. First, 5 of the most severely affected patients in the cohort had tracheostomies and therefore were unable to complete pulmonary spirometry testing, which requires an intact airway and significant

From the Pediatric Oncology Branch (A.M.G., B.C.W.), Center for Cancer Research, National Cancer Institute, NIH, Bethesda, MD; and Department of Neurology and Cancer Center (S.R.P.), Massachusetts General Hospital, Boston.

Go to Neurology.org/N for full disclosures. Funding information and disclosures deemed relevant by the authors, if any, are provided at the end of the article. 
Table Clinical Trial Recommendations From Previous REiNS Publications

\begin{tabular}{|c|c|c|}
\hline $\begin{array}{l}\text { Clinical trial } \\
\text { endpoint }\end{array}$ & Recommended primary outcome measure(s) & Recommended secondary outcome measure(s) \\
\hline $\begin{array}{l}\text { Imaging } \\
\text { response }^{18}\end{array}$ & Volumetric MRI & \\
\hline Pain ${ }^{19}$ & Numeric Rating Scale-11 & \\
\hline $\begin{array}{l}\text { Pain } \\
\text { interference }\end{array}$ & $\begin{array}{l}\text { Pain Interference Index (self-report age } 6-24 \text { y, parent-proxy report } \\
6-18 \text { y) } \\
\text { PROMIS-Pain Interference (age } \geq 18 \text { y) }\end{array}$ & \\
\hline $\begin{array}{l}\text { Physical } \\
\text { functioning }{ }^{19}\end{array}$ & $\begin{array}{l}\text { PROMIS-Physical Functioning (self-report age } \geq 8 \text { y; parent-proxy } \\
\text { report age 5-17y) }\end{array}$ & \\
\hline Visual acuity $^{20}$ & Teller Acuity Cards & $\begin{array}{l}\text { HOTV; Visual Quality of Life (Children's Visual Function } \\
\text { Questionnaire, age } \leq 8 \mathrm{y} \text { ) }\end{array}$ \\
\hline Hearing ${ }^{21}$ & Maximum word recognition score & Pure tone average \\
\hline Facial function ${ }^{21}$ & SMILE analysis & House-Brackmann Scale \\
\hline Sleep ${ }^{4}$ & $\mathrm{AHI}$ & Oxygen saturation, end-tidal $\mathrm{CO}_{2}$, arousal index \\
\hline $\begin{array}{l}\text { Pulmonary } \\
\text { function }^{4}\end{array}$ & $\mathrm{FEV}_{1}\left(\mathrm{FEV}_{0.75}\right.$ for preschoolers); airway resistance at $10 \mathrm{~Hz}\left(\mathrm{R}_{10}\right)$ & $\begin{array}{l}\text { FVC, PEF, forced expiratory flows airway resistance at } 5 \text { and } 20 \\
H z\left(R_{5}, R_{20}\right)\end{array}$ \\
\hline Attention $^{22}$ & $\begin{array}{l}\text { Digit Span WISC-IV (performance based) } \\
\text { Conners Scale (observer rated) }\end{array}$ & \\
\hline
\end{tabular}

Abbreviations: $\mathrm{AHI}=$ apnea-hypopnea index; $\mathrm{FEV}_{1}=$ forced expiratory volume in 1 second; $F \mathrm{FC}=$ forced vital capacity; PEF = peak expiratory flow; $\mathrm{PROMIS}=$ Patient-Reported Outcomes Measurement Information System; REiNS = Response Evaluation in Neurofibromatosis and Schwannomatosis; SMILE = Scaled measurement of improvement in lip excursion; WISC = Wechsler Intelligence Scale for Children.

cooperation from the patient. Therefore, these most severely affected patients were unable to be monitored for subtle changes over time. Second, the baseline degree of dysfunction for some patients, while clearly abnormal, was not always above the threshold needed to eliminate a possible ceiling effect to assess for response. Specifically, this applied to the AHI, a normalized measure of the number of episodes of decreased oxygenation a patient has while sleeping. In pediatric patients, an $\mathrm{AHI}>1$ is considered abnormal; however, to reliably detect change, REiNS recommended to include only patients with an $\mathrm{AHI}>5$ at baseline; none of the patients on the selumetinib clinical trial met this threshold. Therefore, it was not possible to detect significant change in this population with this measure. This raises the question of whether different functional measures might be more suitable to detect subtle changes over time in this patient population.

Despite these challenges, the phase 2 trial of selumetinib successfully used the REiNS recommended volumetric response criteria for its primary endpoint, as well as several of the recommended patient-reported outcome measures, including the Numeric Rating Scale-11 and Pain Interference Index for pain and the Patient-Reported Outcomes Measurement Information System-Physical Functioning questionnaire. The recommendations from the REiNS collaboration were crucial in determining the appropriateness of these measures for our patient population and in establishing accepted thresholds for clinically meaningful change. The Food and Drug Administration (FDA) recently approved selumetinib as the first medical treatment for pediatric patients with inoperable and symptomatic PN primarily on the basis of the results of this trial. Both the pharmaceutical company submitting the new drug application (AstraZeneca) and the FDA commented on the value of the REiNS guidelines. Of note, the FDA itself has contributed to the success of REiNS by attending and contributing their expertise to the biannual REiNS meetings for the last several years, at which they have clarified regulations for drug approval for rare diseases.

In this supplement, we continue to advance this work by presenting additional recommendations for a variety of outcome measures and providing an opportunity to share lessons learned from the successes and challenges that REiNS has encountered since its founding. As noted, the entire REiNS collaboration has made a concerted effort to address cNF over the past several years, and this supplement contains some of the results of that initiative, including (1) an overview of patients' perspectives regarding possible cNF treatment options $^{5} ;(2)$ evaluation of widely available patient-reported outcomes measures for patients with $\mathrm{NF}^{6}{ }^{6}$; (3) assessment of the reliability of digital calipers, 3-dimensional photography, and high-frequency ultrasound for measuring cNF in clinical trials ${ }^{7}$; and (4) an overview of currently available and recommended biomarkers for cNF research. ${ }^{8}$

This supplement also includes assessment and recommendations for the use of patient-reported outcome measures for other NF-related conditions such as disease-specific quality of 
life measures ${ }^{9}$ and measures of hearing-related quality of life for patients with NF2. ${ }^{10}$ In addition, validation of objective assessments of strength (handheld dynamometry), ${ }^{11}$ attention, ${ }^{12}$ and social skills ${ }^{13}$ in patients with NF will provide key guidance across a broad spectrum of NF-related clinical trials. The REiNS biomarker working group presents an overview of current NF genotype-phenotype correlations and how these might be used in future clinical trials. ${ }^{14}$ The REiNS imaging working group presents data on imaging use practices across clinical specialists in NF1. ${ }^{15}$

Last, we are presenting the results of a survey assessing the successes and challenges of our patient representative program from the perspective of both patient representatives and health professionals. ${ }^{16}$ REiNS is a dynamic working group and will use the results from this analysis to more effectively engage patient representatives. At the same time, we hope that our experiences may help other rare disease communities aiming to integrate patient representatives into their research initiatives.

While the articles included in this supplement represent a large portion of the work of the REiNS collaboration over the last several years, there is also much work still being done, including a new working group focusing on skeletal endpoints in NF clinical trials. In addition, the REiNS collaboration intends to continually reassess its previous recommendations in the setting of practical clinical trial experience and to further broaden and diversify the patient representative program. REiNS thus enthusiastically welcomes new members to advance these efforts. ${ }^{17}$ With the recent FDA approval of the first medication for NF1 and so many exciting advances in targeted and other therapies on the horizon, we are optimistic that the recommendations presented here will help facilitate further clinical trials and ultimately improve the way we are able to care for patients with these conditions.

\section{Acknowledgment}

The authors acknowledge the support of the Children's Tumor Foundation for the REiNS International Collaboration.

\section{Study Funding}

The authors report no targeted funding.

\section{Disclosure}

A.M. Gross reports no disclosures relevant to the manuscript. S.R. Plotkin is cofounder of NFlection Therapeutics and NF2 Therapeutics and consults for AstraZeneca and SonalaSense. B.C. Widemann reports no disclosures relevant to the manuscript. Go to Neurology.org/N for full disclosures.

\section{Publication History}

Received by Neurology October 8, 2020. Accepted in final form March 19, 2021.

\section{Appendix Authors}

\begin{tabular}{lll}
\hline Name & Location & Contribution \\
\hline $\begin{array}{l}\text { Andrea M. } \\
\text { Gross, MD }\end{array}$ & $\begin{array}{l}\text { Pediatric Oncology Branch, } \\
\text { National Cancer Institute, } \\
\text { Bethesda, MD }\end{array}$ & $\begin{array}{l}\text { Conceptualized the paper, } \\
\text { author of first draft of } \\
\text { manuscript }\end{array}$ \\
\hline $\begin{array}{l}\text { Scott R. } \\
\text { Plotkin, } \\
\text { MD, PhD }\end{array}$ & Massachusetts General & $\begin{array}{l}\text { Conceptualized the paper, } \\
\text { revised the manuscript for } \\
\text { intellectual content }\end{array}$ \\
\hline $\begin{array}{l}\text { Brigitte C. } \\
\text { Widemann }\end{array}$ & $\begin{array}{l}\text { Pediatric Oncology Branch, } \\
\text { National Cancer Institute, } \\
\text { Bethesda, MD }\end{array}$ & $\begin{array}{l}\text { Conceptualized the paper, } \\
\text { revised the manuscript for } \\
\text { intellectual content }\end{array}$ \\
\hline
\end{tabular}

\section{References}

1. Plotkin SR, Blakely JO, Dombi E, et al. Achieving consensus for clinical trials: the REiNS International Collaboration. Neurology. 2013;81(Suppl):S1-S5.

2. Widemann BC, Plotkin S. Consensus for NF clinical trials: recommendations of the REiNS collaboration (supplement II). Neurology. 2016;87(7):S1-S3.

3. Gross AM, Wolters PL, Dombi E, et al. Selumetinib in children with inoperable plexiform neurofibromas. N Engl J Med. 2020;382(15):1430-1442.

4. Plotkin SR, Davis SD, Robertson KA, et al. Sleep and pulmonary outcomes for clinical trials of airway plexiform neurofibromas in NF1. Neurology. 2016;87(7 suppl 1):S13-S20.

5. Cannon A, Pichard DC, Wolters PL, et al. Perspective of adults with NF1 and cutaneous neurofibromas: implications for clinical trials. Neurology. 2021;97(7):S15-S24.

6. Maguiness S, Berman Y, Rubin N, et al. Measuring the impact of cutaneous neurofibromas on quality of life in neurofibromatosis type 1. Neurology. 2021;97(7):S25-S31.

7. Thalheimer R, Merker VL, Ly KI, et al. Validating techniques for measurement of cutaneous neurofibromas: recommendations for clinical trials. Neurology. 2021;97(7): S32-S41.

8. Wallis D, Stemmer-Rachamimov A, Adsit S, et al. Status and recommendations for incorporating biomarkers for cutaneous neurofibromas into clinical research. Neurology. 2021;97(7):S42-S49.

9. Wolters PL, Vranceanu AM, Thompson HL, et al. Current recommendations for patient-reported outcome measures assessing domains of quality of life in nNeurofibromatosis clinical trials. Neurology. 2021;97(7):S50-S63.

10. Thompson HL, Blanton A, Franklin B, et al. Patient report of hearing in neurofibromatosis type 2: recommendations for clinical trials. Neurology. 2021;97(7): S64-S72.

11. Akshintala S, Khalil N, Yohay K, et al. Reliability of hand-held dynamometry to measure strength in neurofibromatosis type 1 and 2. Neurology. 2021;97(7):S99-S110.

12. Klein-Tasman BP, Lee K, Thompson HL, et al. Recommendations for measurement of attention outcomes in preschoolers with neurofibromatosis. Neurology. 2021; 97(7):S81-S90.

13. Janusz J, Klein-Tasman BP, Payne JM, et al. Recommendations for social skills endpoints for clinical trials in neurofibromatosis type 1. Neurology. 2021;97(7): S73-S80.

14. Bettegowda C, Upadhayaya M, Evans DG, et al. Genotype-phenotype correlations in neurofibromatosis and their potential clinical use. Neurology. 2021;97(7):S91-S98.

15. Ahlawat S, Ly KI, Fayad LM, et al. Imaging evaluation of plexiform neurofibromas in Neurofibromatosis Type 1: a survey-based assessment. Neurology. 2021;97(7): S111-S119.

16. Merker VL, Lessing AJ, Moss I, et al. Enhancing NF trial outcome measures through patient engagement: lessons from REiNS. Neurology. 2021;97(7):S4-S14.

17. National Cancer Institute. REiNS International Collaboration. Accessed October 1 , 2020. https://ccrod.cancer.gov/confluence/display/REINS/Home.

18. Dombi E, Ardern-Holmes SL, Babovic-Vuksanovic D, et al. Recommendations for imaging tumor response in neurofibromatosis clinical trials. Neurology. 2013;81(21 suppl 1):S33-S40.

19. Wolters PL, Martin S, Merker VL, et al. Patient-reported outcomes of pain and physical functioning in neurofibromatosis clinical trials. Neurology. 2016;87(suppl 1): S4-S12.

20. Fisher MJ, Avery RA, Allen JC, et al. Functional outcome measures for NF1-associated optic pathway glioma clinical trials. Neurology. 2013;81(21 suppl 1):S15-S24.

21. Plotkin S, Ardern-Holmes S. Hearing and facial function outcomes for neurofibromatosis 2 clinical trials. Neurology. 2013;81(21 suppl 1):S25-S32.

22. Walsh KS, Janusz J, Wolters PL, et al. Neurocognitive outcomes in neurofibromatosis clinical trials: recommendations for the domain of attention. Neurology. 2016;87(7 suppl 1):S21-S30. 


\section{Neurology}

\section{Neurofibromatosis Clinical Trials--REiNS Collaboration 2020 Recommendations: Looking Back and Moving Ahead \\ Andrea M. Gross, Scott R. Plotkin, Brigitte C. Widemann, et al. Neurology 2021;97;S1-S3 Published Online before print July 6, 2021 \\ DOI 10.1212/WNL.0000000000012429}

\section{This information is current as of July 6, 2021}

\section{Updated Information \&} Services

References

Subspecialty Collections

Permissions \& Licensing

Reprints including high resolution figures, can be found at: http://n.neurology.org/content/97/7_Supplement_1/S1.full

This article cites 21 articles, 20 of which you can access for free at: http://n.neurology.org/content/97/7_Supplement_1/S1.full\#ref-list-1

This article, along with others on similar topics, appears in the following collection(s):

All Clinical trials

http://n.neurology.org/cgi/collection/all_clinical_trials Clinical trials Methodology/study design

http://n.neurology.org/cgi/collection/clinical_trials_methodology_study design

Neurofibromatosis

http://n.neurology.org/cgi/collection/neurofibromatosis

Information about reproducing this article in parts (figures,tables) or in its entirety can be found online at:

http://www.neurology.org/about/about_the_journal\#permissions

Information about ordering reprints can be found online:

http://n.neurology.org/subscribers/advertise

Neurology ${ }^{\circledR}$ is the official journal of the American Academy of Neurology. Published continuously since 1951, it is now a weekly with 48 issues per year. Copyright (O) 2021 American Academy of Neurology. All rights reserved. Print ISSN: 0028-3878. Online ISSN: 1526-632X.

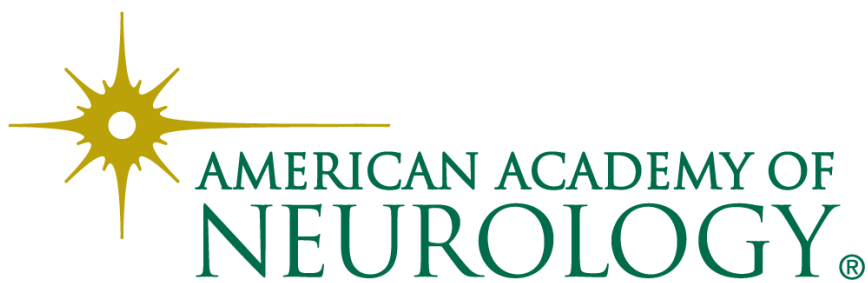

